УДК 34

12.00.00 Юридические науки

КРИМИНАЛИСТИЧЕСКАЯ

ПРОФИЛАКТИКА ПО КОНКРЕТНОМУ УГОЛОВНОМУ ДЕЛУ О НЕЗАКОННОМ ОБОРОТЕ НАРКОТИКОВ

Меретуков Гайса Мосович

доктор юридических наук, профессор, заведующий кафедрой криминалистики

Лунина Евгения Станиславовна кандидат юридических наук, доцент кафедры криминалистики

Бирюкова Сусана Николаевна студентка 4 курса заочного обучения юридического факультета ФГБОУ ВО «КубГАУ им. И.Т. Трубилина», Краснодар, Россия

В статье авторы анализируют состояние криминалистической профилактики в специальной юридической литературе, при этом проводит анализ отдельных положений норм УПК России, позволяющие осуществлять профилактическую деятельность следователя в процессе расследования уголовных дел. В частности автор рассматривает про фактическую деятельность следователя применительно к расследованию незаконного оборота наркотических средств. По научной статье учтены мнения известных ученых Р.С. Белкина, С.А. Голунского, А.Н. Колесниченко, И.А. Возгрина, И.И. Иванова и других

Ключевые слова: КРИМИНАЛИСТИКА; ПРОФИЛАКТИКА; УГОЛОВНОЕ ДЕЛО; НЕЗАКОННЫЙ ОБОРОТ НАРКОТИКОВ; СЛЕДОВАТЕЛЬ; ПОДОЗРЕВАЕМЫЙ

Doi: 10.21515/1990-4665-128-057
UDC 34

Legal sciences

\section{CRIME PREVENTION IN A PARTICULAR CRIMINAL CASE ABOUT DRUG TRAFFICKING}

Meretukov Geiss Mosovich, Doctor of legal Sciences, Professor, head of the Department of criminology

Lunina Eugenia Stanislavovna

Candidate of legal Sciences, associate Professor of criminology

Biryukova Susana Nikolaevna 4th year student of extramural studies of the law faculty

Kuban State Agrarian University, Krasnodar, Russia

In the article the authors analyze the state of crime prevention in special legal literature, with analyses certain provisions of the criminal procedure code of Russia, allowing carrying out the preventive activities of the investigator during the investigation of criminal cases. In particular, the authors discuss the actual activities of the investigator in relation to the investigation of illicit trafficking in drugs. In the scientific article we have taken into account the views of famous scientists: R. S. Belkin, S. A. Solunskogo, A. N. Kolesnichenko, I. A. Vozgrin, I. I. Ivanov and others

Keywords: FORENSIC SCIENCE; PREVENTION; CRIMINAL CASE; DRUG TRAFFICKING; INVESTIGATOR; SUSPECT

В конце прошлого и начала XXI века происходившие в стране противоречивые процессы в области экономики и политики, не могли не сказаться на количественном и качественном состоянии преступности, активизация роли «воров в законе» на формирование психологии неустойчивых лиц из числа спортсменов, занимающихся боксом, вольной борьбой, самбо, спортивной стрельбой и т.д.), а также ранее судимых, за счет чего сформировались организованные преступные группы, которые 
реагировали на их изменения в своей динамике, структуре и характере. В соответствии с этими процессами можно выделить два периода с характерными особенностями: до 1990 годов под тоталитарным социальным контролем преступность находилась в состоянии постепенного роста, а после 1990 года демократизация государства, открытие границ, раскрепощение народа, резкое увеличение преступности (появились новые виды преступного деяния в сфере экономической деятельности, в сфере компьютерных и новых информационных технологий, налоговые преступления, получило совершенствование по способу совершения мошенничества, вымогательства, убийств по найму и т.д.).

В это же время частичный отход деятельности от приоритетной направленности полиции и полный отказ от профилактики уголовнопроцессуальными мерами.

В этот период, состояние преступности в стране представляло собой характеристику постоянного увеличения по количеству и качеству, которое влияло на состояние правопорядка, личной и общественной безопасности. Этому способствовали криминальные факторы экономического характера (сложная ситуация в финансово-хозяйственной сфере; результаты неправильной приватизации; резкое расслоение населения по имущественному характеру; преобладание импортных товаров над экспортом, варварское уничтожение самих хозяйств и легкой, пищевой и тяжелой промышленности и т.д.); слабая социальная защищенность границы, низкие уровень жизни, сосредоточение основной части финансового потока и основной части населении в столице и конкретных городах страны, высокий уровень безработицы в других городах и сельской местности страны. Основные политические факторы были и остаются: не преемственность политики государства в борьбе с преступностью, наличие коррупции и т.д. 
(все это прослеживается, например, неоднократные реорганизации МВД и Генеральной прокуратуры, создание регионального управления по борьбе с организованной преступной и налоговой полицией, госнаркоконтроля, миграционной службы, которые в последствии ликвидированы и возвращены в структуру МВД, Кроме этого созданный следственный комитет, расследует уголовные дела от 9до13\% от общего массива возбужденных дел в стране, а в это время следователи МВД от 77 до 82\% всего массива предварительного расследования (См.: Состояние преступности по данным ГИАЦ МВД РФ по состоянию с 2010 по 2016 гг.). Возникает вопрос, надо ли было тратить огромные денежное и моральное состояния при реорганизации Генпрокуратуры России. К сожалению, как нам приставляется, такие реорганизации законодательного и структурного характера повлияли на утрату профилактической деятельности органов предварительного следствия и дознания.

Вместе с тем, Федеральным законом от 2 декабря 2008 года №226 Ф3 в ст.158 УПК РФ (окончание предварительного следствия) дополнил ч.2 в котором предписано, что следователь, дознаватель и руководитель следственного органа должны выявлять обстоятельства, способствовавшие совершению преступления и вносить представления по их устранению. Таким образом, орган предварительного следствия и дознания получил основание и механизм реализации ч.2 ст.73 УПК РФ (обстоятельства, подлежащие доказыванию).

Правовой основой криминалистической профилактики, на мой взгляд является положение норм УПК России. Например, ч.2 ст.73 УПК России гласит, что «подлежат выявлению также обстоятельства, способствовавшие совершению преступления», а также ч.2 ст.158 УПК России представляет, что «установив в ходе досудебного производства по уголовному делу обстоятельства, способствовавшие совершению преступления, дознаватель, руководитель следственного органа, 
следователь вправе в соответствующую организацию или соответствующему должностному лицу представление о принятии мер по устранению указанных обстоятельств или других нарушений закона. Данное представление подлежит рассмотрению с обязательным уведомлением о принятых мерах не позднее одного месяца со дня его вынесения. Этим можно объяснить то, что криминалистическая профилактика имеет правовую основу.

Р.С. Белкин в одной из своих работ аргументируя понятие термина «Следственная тактика» пишет, что это - «Система научных положений и разрабатываемых на ее основе рекомендаций по организации и планированию предварительного и судебного следствия, определению линии поведения лиц, осуществляющих судебное исследование, и приемов проведения отдельных процессуальных действий, направленных на собирание и исследование доказательств на установление причин и условий, способствующих совершению и сокрытию преступлений»[1].

Bсе таки, Р.С. Белкин обращает внимание на криминалистическую профилактику через обстоятельства, подлежащих доказыванию т.е., «подлежат выявлению также обстоятельства, способствовавшие совершению преступления (ч.2 ст.73 УПК РФ) включая в определение понятие «следственная тактика».

В основополагающем термине «Криминалистика» Ганс Гросс во второй половине XIX века высказал мнение о важности установления в процессе расследования обстоятельств способствовавших совершению каждого преступления и подверг разной практике теорию Ломброзо[2]. В отечественной криминалистике также уделено внимание криминалистической профилактике такими известными учеными, как Б.М. Шавер, С.А. Голунский, П.И. Тарьков-Радионова, Н.В. Терзиев, А.Н. Васильцев, С.П.Митричев, В.П. Колмаков, А.Н. Колесниченко, И.А. Возгрин [3] и др. 
Вместе с тем автору известны две фундаментальные работы одна докторская, а другая кандидатская, посвященные криминалистической профилактике преступлений, как комплексное научно-теоретическое и практическое исследование.

Например И.И. Иванов по своим материалам докторской диссертации написал монографию на тему: Криминалистическая превенция (генезис, теоретические и методологические основы, перспективы развития в свете нового уголовно-процессуального законодательства) и криминалистическая профилактика преступлений(комплексное научно-практическое исследование в котором рассмотрены понятие превенции преступлений и его исследование в различных отраслях юридического знания, зарождение, развитие и современное понятие криминалистической превенции, состояние и перспективы и проблемы практики криминалистической превенции [4].

В криминалистической науке рассмотрено частное криминалистическое учение о профилактике преступлений несовершеннолетних.

Например Ю.Н. Аксенова-Сорохтей достаточно глубоко рассмотрела исторические и научные основы формирования частного криминалистического учения о профилактике преступлений несовершеннолетних (исторические предпосылки и современные реалии формирования частного криминалистического учения о профилактике преступлений несовершеннолетних, соотношение криминалистической характеристики преступлений и частного криминалистического учения о профилактике преступлений несовершеннолетних; современное состояние и перспективы взаимодействия следователя с другими участниками профилактики преступлений)[5].

В частности Ю.Н. Аксенова-Сорохтей пишет, что криминалистическая профилактика преступлений несовершеннолетних - 
это «Частное криминалистическое учение, которое имеет свои специфические атрибуты: объект, предмет, методы, как систему приемов для определения условий, способствующих совершению несовершеннолетними преступлений, и направлений, позволяющих оптимизировать прохождение криминалистически значимой информации, полученной следователем при расследовании преступлений, о факторах, влияющих на динамику совершения преступлений несовершеннолетними, к другим участникам профилактики подростковой преступности, а также основные принципы взаимодействия всех субъектов профилактики несовершеннолетних» [6].

Предложенное Ю.Н. Аксеново-Сорохтей мнение о криминалистической профилактики несовершеннолетних, предполагает о возможности адаптировать и использовать применительно к любому конкретному лицу совершившего конкретного вида преступление.

Анализ мнений ученых позволил автору прийти к выводу, что в структуру криминалистической профилактики определенного вида преступлений возможно включить характер конкретных преступлений: способы совершения и сокрытия преступлений; характеристику личности жертвы; доступность для оперативного внедрения; соотношение следственнокриминалистической и оперативно-розыскной характеристики.

Для совершенствования криминалистической профилактики преступлений необходимо рассмотреть следующие направления и элементы организационной основы профилактической деятельности следователя: совершенствование уголовного и уголовно-процессуального законодательства, отдельные направления криминалистической науки и теории ОРД, в том числе определение места этих наук в системе профилактики преступлений; совершенствование повторного и постоянного обучения (специализация) кадров органов предварительного следствия и дознания, в частности подразделений органов 
осуществляющих оперативно-розыскную деятельность; научнотехническое совершенствование органов предварительного следствия и дознания; в целях обеспечения принятия мер устранение причин и условий способствовавшие совершению преступлений необходимо в каждом разделе курса криминалистики с учетом своих специфичных возможностей включить элементы профилактической деятельности по выявлению и доказыванию причин и условий совершения конкретного преступления; выявление всех обстоятельств, способствовавших совершению преступления; оптимальная разработка, подготовка и проведение всех доступных следователю профилактических мероприятий по устранению выявленных причин и условий, способствовавших совершению преступления, а также по ликвидации тех дефектов, которые повлияли на появление этих обстоятельств; системный подход к выявлению, изучению и устранению всех причин и условий, способствовавших совершению преступления; выявление всех последствий совершенного преступления; использование следователем для сбора информации всех звеньев общей системы социальной профилактики; осуществление госпитального воздействия непосредственно в ходе предварительного следствия; своевременное выявление подготавливаемых преступлений, их предупреждение в процессе расследования; конкретизация и концентрация тактических средств осуществления профилактической деятельности следователя. На различных этапах профилактической деятельности следователь должен решить следующие тактические задачи: выявление дефектов в элементах структуры преступления; выявление причин появления этих дефектов; планирование профилактической деятельности следователя; определение субъектов профилактической деятельности; разработка и внесение представления; анализ и контроль результатов проведенных профилактических мероприятий. 
Средствами разрешения по установлению причин и условий совершения преступлений могут быть следственные действия; розыскные мероприятия; тактические операции; поручения органам дознания; поручения другим государственным органам и организациям; привлечение общественности.

Важность изучения профилактической деятельности следователя определяется тем, что он является обязательным субъектом системы социальной профилактики преступлений. В основном, деятельность следователя направлена на выявление причин и условий, способствовавших совершению преступления, на стадии предварительного расследования является основанием для направленности и активизации деятельности других субъектов социальной профилактики преступлений. В процессе выявления причины и условия непосредственно влияющие на совершение конкретного преступления следователь в состоянии определить и выявить пробелы и недостатки в деятельность должностных лиц, которые допустили к появлению этих причин и условий.

Успех профилактики преступлений во многом зависит и от разработки системы тактических средств, осуществления профилактической деятельности следователя требует определения роли отдельных следственных действий и тактических операций для решения профилактических задач в ходе расследования.

Как правило, следователь включается в деятельность системы профилактики на том этапе, когда дефекты в управлении, распределении, сбои в технологических процессах уже проявили себя в качестве преступления.

К числу недостаточно исследованных проблем следует отнести определение содержания целей и принципов профилактической деятельности, тактических средств, используемых для выявления причин преступлений, и условий, способствовавших определению роли отдельных 
тактических операций, а также изучение личности обвиняемого и значение местного воспитательного воздействия следователя, вопросы взаимодействия следователя с другими субъектами профилактики, а также некоторые специальные для дел связанных к основной форме профилактического реагирования.

Изложенное позволяет предположить о необходимости проведения индивидуальной профилактики конкретных преступлений, a также выявлении лиц, склонных к совершению преступлений и их постановки на криминалистический учет, кроме этого, по мнению авторов, профилактика должна быть направлена на пресечение преступлений на стадии формирования умысла, приготовления к преступлению, покушения на преступление.

Исходя из изложенного авторы считают возможным предложить профилактическую деятельность следователя при расследовании преступлений, связанных с наркобизнесом по конкретному уголовному делу [7].

Работа по борьбе с наркоманией должна проводиться во взаимодействии органа предварительного следствия и органа дознания с другими заинтересованными ведомствами и общественность. При расследовании уголовного дела данной категории важнейшей задачей является полное раскрытие преступления, выявление всех лиц, причастных к фактам потребления наркотиков. Устанавливая таких лиц, необходимо выяснить условия, способствовавшие приобщению их к приему наркотиков, возможности незаконно получить рецепты или сам наркотик, подделать, изготовить печати. Особое внимание следует уделять недостаткам в учете и хранении рецептурных бланков и наркотических средств: охране полей наркотикосодержащих культур, выявлению и уничтожению дикорастущих растений, являющихся сырьем для изготовления наркотика, и многим другим условиям и обстоятельствам, 
которые способствуют незаконному изготовлению, приобретению, хранению, перевозке или сбыту наркотических средств.

В целях предупреждения хищения, нарушения установленных правил хранения, учета, отпуска наркотиков в медицинских учреждениях работниками подразделений по борьбе с незаконным оборотом наркотических средств и борьбе с экономическими преступлениями должны быть проверены наличие и правильность оформления следующих документов: акты передачи, накладные, отчеты о приходе и расходе наркотических средств; приказ медицинского учреждения о назначении ответственного за выписывание допущенных к введению наркотических и сильнодействующих средств, согласованный с руководством горрайоргана внутренних дел; приказ о назначении ответственного за получение рецептурных бланков; журнал учета приема использованных ампул из-под наркотических средств; приказ о назначении ответственного за хранение наркотических средств и рецептов; книгу учета рецептурных бланков, образцы печатей и подписей.

В соответствии с этими документами проверяется: обеспечивается ли сохранность наркотика при хранении и перевозках (сигнализация, сейфы и т.д.); откуда, какого вида получены наркотики, сколько и в какой упаковке; какое количество наркотика возвращено после использования его по назначению; где хранятся наркотики, кто из медперсонала имеет доступ к ним, каков порядок их отпуска, приемки и списания; имелись ли раньше факты хищения наркотиков; причины и условия, способствующие хищению наркотиков.

В случае установления хищения, нарушения установленных правил учета, хранения, отпуска и других фактов составляется протокол осмотра рабочего места, приходные документы сличаются с журналом учета приема использованных ампул; рецепты с историей болезни больных или амбулаторной картой; печати и подписи на рецептах с приказом на право 
выписывания рецептов и право введения наркотических средств; в протоколе изъятия указывается наименование упаковки с ампулами, количество ампул в упаковке и их название, надписи, имеющиеся на ампуле или упаковке, размеры ампул и т.д.

В профилактике незаконного оборота наркотических средств наркобизнеса существенное значение прежде всего имеют своевременное выявление этих преступлений, задержание и обоснованная мера пресечения. Наблюдение указанных требований вселяет в подозреваемого (преступника) уверенность в безнаказанности и создает возможность для продолжения преступной деятельности.

В процессе расследования каждого дела о наркомании должны быть изучены все обстоятельства, способствовавшие преступлению. При этом подлежат установлению обстановка преступления; предмет преступного посягательства; способы совершения и скрытия преступления; особенности следов, оставленных преступниками (механизм следообразования), личность преступника (его поведение при совершении преступления и во время расследования); источники приобретения наркотикосодержащего сырья и наркотиков; допущенные нарушения законов и ведомственных правил, регламентирующих условия производства, приобретения, хранения, учета, отпуска, перевозки или пересылки наркотических средств.

При выявлении недостатков в организации борьбы с данной преступностью, фактов попустительства или содействия лицам, занимающимся незаконным оборотом наркотиков, со стороны должностных лиц незамедлительно должны быть приняты меры к их устранению и привлечению виновных, в зависимости от содеянного к дисциплинарной, административной и уголовной ответственности.

В процессе расследования необходимо также выявить лиц, которые оказали содействие при незаконном изготовлении, приобретении, 
хранении, перевозке или сбыте наркотических средств; соучастников, их преступные связи и информировать об этом работников соответствующих служб для принятия профилактических мер.

В частности, это поможет проведению индивидуальной профилактики в отношении лиц, склонных к совершению правонарушений, связанных с наркотиками, а также злоупотребляющих наркотическими средствами.

Основными составными элементами индивидуальной профилактики являются:

Выявление и постановка на учет лиц, обоснованно подозреваемых в совершении правонарушений, связанных с наркотиками, либо допускающих немедицинское потребление наркотических средств и нарушающих общественный порядок или права других граждан; осуществление контроля за их дальнейшим поведением; принятие конкретных мер воспитательного, медицинского, правового и оперативнорозыскного характера с целью побуждения профилактируемых к добровольному отказу от совершения правонарушений на этой почве; устранение причин и условий, которые способствуют совершенствованию правонарушений.

Выявление лиц, нуждающихся в профилактическом воздействии обязанность сотрудников всех служб органов внутренних дел. Такие лица выявляются в процессе повседневной профилактической, оперативнорозыскной, административной и следственной работы. Их выявление должно быть целенаправленным, максимально ранним и полным.

Лица данной категории прежде всего выявляется среди: отбывающих и отбывших наказание в ИТУ и в первую очередь за деяние, связанные с наркотиками; подвергнутых исправительным работам, осужденных к лишению свободы условно либо с отсрочкой исполнения приговора; совершивших преступления, но освобожденных от уголовной 
ответственности и наказания; подвергнутых наказанию в административном порядке за приобретение или хранение наркотических средств в небольших размерах, незаконный посев или выращивание масличного мака и конопли; освобожденных от административной ответственности; проходящих или прошедших принудительное лечение от наркомании в условиях ИТУ; несовершеннолетних и молодежи из группы повышенного риска, неформальных объединений молодежи, ориентированных на потребление наркотиков; занимающихся незаконным врачеванием либо самолечением с применением средств народной медицины, обладающих наркотическим действием; работников химикофамацевтических предприятий, аптек, медперсонала.

Для своевременного получения информации о таких лицах устанавливается деловая и постоянная связь с: режимными (оперативнорежимными) частями ИТУ в отношении осужденных, замеченных в употреблении наркотиков; осужденных за преступления, связанные с наркотиками и проявляющие стремление продолжать аналогичную преступную деятельность на «свободе», проходящих принудительное лечение от наркомании в условиях ИТУ и допускавших попытки незаконного приобретения наркотиков; районной (городской) наркологической службой и их структурными подразделениями в отношении граждан, допускающих немедицинское потребление наркотиков, выявленных по их инициативе; станциями «скорой помощи», токсикологическими, травматологическими, реанимационными пунктами в отношении лиц, поступающих к ним в состоянии наркотического опьянения; онкологическими диспансерами и иными лечебными учреждениями в отношении больных, которым лечащий врач назначает наркотики для приема на дому, что не исключает возможность немедицинского потребления данных лечебных средств другими лицами из числа родственников этих больных либо иными гражданами, которым 
могут передаваться наркотики для медицинского приема за определенное вознаграждение; лечебно - профилактическими учреждениям в отношении потребителей наркотиков, выявленных ими при медицинском обследовании молодежи призывного возраста, систематически диспансеризациях населения, при неоднократном обращении отдельных граждан с просьбой назначить лекарственные средства с наркотическим действием; здравпунктами общеобразовательных школ, ПТУ, техникумов, вузов в отношении учащихся, взятых на учет в связи с возможностью потребления наркотиков либо совершения правонарушений, связанных с наркотиками; горрайвоенкоматами в отношении граждан, не призванных в ряды вооруженных сил в связи с немедицинским потреблением наркотиков; иными органами в отношении лиц, употребляющих наркотически средства, выявленных ими в процессе правоприменительной и иной деятельности.

Основанием для постановки на профилактический учет являются: совершение лицом правонарушения, связанного с наркотическими средствами, за которое оно понесло наказание и дальнейшее его поведение свидетельствует о возможном рецидиве; наличие антиобщественных поступков, указывающих на стремление к совершению противоправных деяний с наркотическими средствами. Лица, злоупотребляющие наркотическими средствами и нарушающие общественный порядок или права других граждан, в обязательном порядке ставятся на учет, прежде всего с целью установления источников и каналов приобретения ими наркотиков. Информация о таких лицах излагается в паспорте на имя начальника горрайлиноргана и докладывается ему для принятия соответствующего решения.

При проведении работы с профилактируемыми необходимо учитывать положительные и отрицательные свойства их личности, характер и степень общественной опасности совершенных ими 
правонарушений, сведения о связях, при этом методы убеждения должны сочетаться с мерами правового, воспитательного и медицинского воздействия и применяться в строгом соответствии с действующим законодательством.

Проведение индивидуально-профилактической работы предусматривает: наблюдение за поведением и образом жизни профилактируемых в семье, быту и по месту работы: реагирования на правонарушения и иные противоправные действия: принятие мер в отношении лиц, провоцирующих профилактируемого на потребление наркотиков и совершение правонарушений.

Профилактируемому оказывается необходимая помощь в трудоустройстве (поступлении на учебу), адаптации в новом трудовом (учебном) коллективе: нормализации семейно-бытовых отношений; принятии мер о прохождении курса добровольного лечения от наркомании или токсикомании; смене круга общения; приобщении к социальнополезным занятиям и т.п.

Реагирование на сигналы о совершении подучетными правонарушений и других противоправных деяний, связанных с наркотическими средствами, должно быть своевременным и адекватным.

В отношении лиц, обосновано подозреваемых в совершении преступлений, осуществляются оперативно-розыскные мероприятия, в том числе профилактические, которые проводятся в строгом соответствии с Законом об оперативно-розыскной деятельности.

Получение при допросах свидетелей, обвиняемого сведения о возможных местах хранения предметов преступления, преступных связях и преступлениях, подготавливаемых или совершенных другими лицами, после их проверки могут служить базой для неотложных профилактических действий. 
На стадии расследования дела о наркомании следователь в необходимых случаях праве давать органам дознания поручения и указания о выяснении обстоятельств, существенных для пересечения и предупреждения преступления.

В более полном объеме предупредительные мероприятия осуществляются по материалам оконченного дела. Основным процессуальным способом профилактики наркомании на этом этапе является представление следователя об устранении причин и условий, способствовавших совершению преступления (ст. 140 УПК РФ).

Важной формой профилактической работы следователя по материалам уголовного дела о наркомании является выступление перед населением по месту жительства, перед коллективом предприятия, где работал преступник, с целью выявить недостатки, способствовавшие преступлению.

Необходимо также, периодически выступая перед общественностью, детально анализировать недостатки и упущения, обусловившие преступление, обсудить направления профилактической работы и меры по усилению борьбы с лицами, ведущими паразитический образ жизни, занимающимися незаконным оборотом наркотиков, содержанием притонов и сводничеством.

Анализ научной и специальной литературы, а также следственная практика позволяет предложить определение понятия «Криминалистическая профилактика преступления» - это осуществление органом предварительного следствия и дознания организационно упорядоченного процесса проведения мероприятий, основанного на применении обычных (гласных) и специальных (негласных) методов, комплексном использовании сил и средств, направленных на выявление и устранение факторов, способствующих совершению преступлений, выявление реальных и потенциальных участников преступлений, 
реализующих уголовно-правовые и процессуальные нормы в отношении них мер, исключающих возможность совершения преступлений.

\section{Литература:}

1. Белкин Р.С. Курс криминалистики. 3-е изд. Дополн. М., 2001.С.194.

2. Ганг Гросс, Руководство для судебных следователей членов общей и жандармской полиции. Смоленск, 1895 и на ее основе Руководство для судебных следователей как система криминалистики. (СПб., 1908) - СПб, 2002.c.13-17 и 133 145.

3. Шавер Б.М. Предмет и метод советской криминалистики//соч.законность, М., 1938 №6.c.70; Голунский С.А., Расчинский Г.К. Техника и методика расследования преступлений. Выпуск№2, М., 1934; Тарасов - Радионов П.И., с.7,11-13; Терзиев Н.В. К вопросу о системе науки советской криминалистики//Правоведение, М., 1961 №2.c.152 и 155; Васильев А.Н. Предмет криминалистики//соц.законность, М., 1967 №1 с.30-33; Митричев С.П. Предмет советской науки криминалистики и е место в системе юридических наук//соц. Законность, 1952. №3.c.26; Колмаков В.П. Преодолеть отставание в разработке вопросов советской криминалистики //Соц. Законность, 1952. №2.c.30-31; Колесниченко А.Н. Общие положения методики расследования отдельных видов преступлений (текст лекции). Харьков, 1976.c.7; Возгрин И.А. Криминалистическая методика расследования преступлений. Минск, 1983.c.212 и др.

4. Иванов И.И. Криминалистическая превенция (генезис, теоретические и методологические основы, перспективы развития в свете нового уголовнопроцессуального законодательства): Монография/под ред. И.А. Возгрин. СПб.:Спб университет МВД России, 2003.-140 с.; Ивнов И.И. комплексное научно-практическое исследование): Монография/под ред. И.А. Возгрин. СПб.: СПб университет МВД РФ, 2004.-320c.

5. Аксенова- Сорохтей Ю.Н. Частное криминалистическое учение о профилактике преступлений автореф.дис.канд.юрид.наук.Воронеж.2011

6. Аксенова-Сорохтей Ю.Н. Указ.соц.с.24.

7. Излагается по материалам докторской диссертации Меретукова Г.М. «Правовые и криминалистические проблемы борьбы с наркобизнесом, совершаемых организованными преступными группами». Дисс. Докт. Наук.:М.1995.

\section{References}

1. Belkin R.S. Kurs kriminalistiki. 3-e izd. Dopoln. M., 2001.S.194.

2. Gang Gross, Rukovodstvo dlja sudebnyh sledovatelej chlenov obschej i zhandarmskoj policii. Smolensk, 1895 i na ee osnove Rukovodstvo dlja sudebnyh sledovatelej kak sistema kriminalistiki. (SPb., 1908) - SPb, 2002.s.13-17 i 133 - 145.

3. Shaver B.M. Predmet i metod sovetskoj kriminalistiki//soch.zakonnost', M., 1938 №6.s.70; Golunskij S.A., Raschinskij G.K. Tehnika i metodika rassledovanija prestuplenij. Vypusk№2, M., 1934; Tarasov - Radionov P.I., s.7,11-13; Terziev N.V. K voprosu o sisteme nauki sovetskoj kriminalistiki//Pravovedenie, M., 1961 №2.s.152 i 155; Vasiljev A.N. Predmet kriminalistiki//soc.zakonnost, M., 1967 №1 s.30-33; Mitrichev S.P. Predmet sovetskoj nauki kriminalistiki i e mesto v sisteme juridicheskih nauk//soc. Zakonnost, 1952. №3.s.26; Kolmakov V.P. Preodolet otstavanie v razrabotke voprosov sovetskoj kriminalistiki 
//Soc. Zakonnost, 1952. №2.s.30-31; Kolesnichenko A.N. Obshhie polozhenija metodiki rassledovanija otdelnyh vidov prestuplenij (tekst lekcii). Harkov, 1976.s.7; Vozgrin I.A. Kriminalisticheskaja metodika rassledovanija prestuplenij. Minsk, 1983.s.212 i dr.

4. Ivanov I.I. Kriminalisticheskaja prevencija (genezis, teoreticheskie i metodologicheskie osnovy, perspektivy razvitija $\mathrm{v}$ svete novogo ugolovno-processual'nogo zakonodatelstva): Monografija/pod red. I.A. Vozgrin. SPb.:Spb universitet MVD Rossii, 2003.-140 s.; Ivnov I.I. kompleksnoe nauchno-prakticheskoe issledovanie): Monografija/pod red. I.A. Vozgrin. SPb.: SPb universitet MVD RF, 2004.-320s.

5. Aksenova- Sorohtej Ju.N. Chastnoe kriminalisticheskoe uchenie o profilaktike prestuplenij nesovershennoletnih: avtoref.dis.kand.jurid.nauk.Voronezh.2011

6. Aksenova-Sorohtej Ju.N. Ukaz.soc.s.24.

7. Izlagaetsja po materialam doktorskoj dissertacii Meretukova G.M. «Pravovye i kriminalisticheskie problemy borby $\mathrm{s}$ narkobiznesom, sovershaemyh organizovannymi prestupnymi gruppami». Diss. Dokt. Nauk.:M.1995. 